\title{
Analysis of M-Commerce in China
}

\author{
Jian Tong Cao, Yi Xiang Tong, Zhi Ke Che, and Xiao Li \\ Beijing University of Posts \& Telecommunications \\ Email: tony000@263.net
}

\begin{abstract}
Extended Abstract: With the development of mobile service, more and more $\mathrm{M}$-commerce applications have been adopted in China. The government also encourages this trend, as presented in its policies. In this paper, four major business model of M-commerce will be introduced to analyze the applications in China. These four models are B-B-E (Employee), B-B-M (Machine), B-B-P (Promotion), B-B-C (Consumer). Examples of each model will be presented after the definition of each model.
\end{abstract}

The first model is B-B-E. The first B refers to mobile operator, the second $B$ refers to enterprise or government, the $E$ means employees of the enterprise or government. In this model, a wireless connection is an obvious prerequisite for employees to gain access to their enterprise applications. Wireless connectivity can be enabled through a wide range of technologies, such as smart-phone and PDA using standard mobile data networks (currently China Mobile's GPRS and China Unicom's CDMA1X), PC data cards etc. Once connected, enterprise employees can access the internet, the company intranet or take advantage of mobile data solutions that may be integrated with their enterprise systems. For B-B-E model, the most famous application in China is in the government sector, originally from Beijing East District Government. With the B-B-E solution, government staffs with mobile device support were sent to the street to report problem and interact with citizens, which significantly improve the efficiency. The solution is based on two management centers, connecting with nearly 400 municipal asset management staffs. With GIS system, the district area will be divided into $100 \mathrm{~m} * 100 \mathrm{~m}$ square grid with specified numbered municipal assets. The municipal asset management staffs will use the mobile device (also has GPS function) to go around the grids to report, interact with citizens, and solve the asset problems.

Please use the following format when citing this chapter:

Tong Cao, J., Xiang Tong, Y., Kc Che, Z., Li, X., 2006, in International Federation for Information Processing, Volume 205, Rescarch and Practical Issues of Enterprise Information Systems, eds. Tjoa, A.M., Xu, L., Chaudhry, S., (Boston:Springer), pp.691-693. 
The second model is B-B-M. The first B refers to mobile operator, the second $B$ refers to enterprise or government, the $M$ means machine of the enterprise or government. This model is an example of remote asset monitoring often used in some industries such as vehicle and retail. In this model, a combination of wireless connection and information collection technologies is built into the machines, which allow the enterprise or government to know the real time status information of their widespread machines. In the future, with the development of RFID technologies, the model can be extended to product monitoring market. In recent years, electronic usage in China, especially in eastern area such as Guangdong province are increasing rapidly, but the supply capacity can not meet these increase easily. So in 2005, Guangdong Electronic Utility Management Bureau introduced one B-B-M solution to collect customer electronic real time usage information, which can be used to balance the gap between requirement and capacity. When the total electronic utility reaches some specified level, the Bureau will sent SMS (Short Message) to the customers which has use more electronic than specified or electronic un-sensitive enterprises to reduce their usage as soon as possible, so the total utility will return to normal level.

The third model is $\mathrm{B}-\mathrm{B}-\mathrm{C}$. The first $\mathrm{B}$ refers to mobile operator, the second $B$ refers to enterprise or government, the $C$ means the customers of the second $\mathrm{B}$, which can be consumer and enterprises. The major difference between this model and the former model is that the wireless connection has extended outside the enterprise. In this model, the enterprise which has public information such as Meteorological Agency will allow their customers to get their information through wireless connections provided by mobile operators. The customers must pay to mobile operator to get the information, the mobile will payback some of this information income to the enterprises which own the information. Now, the most popular B-B-C model application is in the meteorological area. Because the meteorological information is useful for all customers, the customers are willing to pay some money to get the information through mobile network easily.

The last model is B-B-P. The first B refers to mobile operator, the second $\mathrm{B}$ refers to enterprise or government, the $\mathrm{P}$ means promotion. In this model, the enterprise will use the wireless connections to extend their current CRM (Customer Relationship Management) and SCM (Supply Chain Management) system, allowing their customers or supplies to access their CRM and SCM system through wireless connections provided by mobile operators. In this model, the customers and supplies are free of charge to get the information provided by the enterprise or government. This model is different from B-B-C model in the payment mechanism. For example, in recent months, there are more and more finance fraud cases (use mobile short message) in China. But only one bank named China Merchants Bank don not report one case, just because it has used one B-B-P solution to completely avoid the fraud. 
The most promising model is $\mathrm{B}-\mathrm{B}-\mathrm{C}$, because of its huge customer base and potential income. So the mobile operators must first figure out which enterprise or government customer has the unique information, and build the cooperation model as soon as possible. The B-B-P model is more difficult because the free charge mechanism.

The B-B-M model is also the next trend. With the upcoming of $3 \mathrm{G}$ and IP V6 technologies, this model will extend to every good, such as products and animals.

The B-B-E model is the traditional one, which is focusing on in-house application. The future of this model is the extension of current IT system to mobile technologies.

In conclusion, the $\mathrm{M}$-commerce has the potential to become an important source of high-margin revenues for China operators. To achieve these growth opportunities, the operators should have well-defined strategy, the right partnerships and the internal capabilities required for success in this emerging but rapidly growing market segment.

\section{References}

1. www.mii.gov.cn.

2. Annual Report of China Mobile and China Unicom, 2004.

3. China Construction Daily 2005-7-26. 